\title{
Gut Microbe-Mediated Suppression of Inflammation-Associated Colon Carcinogenesis by Luminal Histamine Production
}

Chunxu Gao, ${ }^{* \dagger}$ Bhanu Priya Ganesh, ${ }^{\dagger \dagger}$ Zhongcheng Shi, ${ }^{\dagger \dagger}$ Rajesh Rasik Shah, ${ }^{\dagger}$ Robert Fultz,${ }^{\dagger \S}$ Angela Major, ${ }^{\dagger}$ Susan Venable, ${ }^{* \dagger}$ Monica Lugo, ${ }^{{ }^{\dagger}}$ Kathleen Hoch, ${ }^{\dagger}$ Xiaowei Chen, ${ }^{\top}$ Anthony Haag, ${ }^{* \dagger}$ Timothy C. Wang, ${ }^{\natural}$ and James Versalovic ${ }^{* \dagger}$

\begin{abstract}
From the Department of Pathology and Immunology, ${ }^{*}$ the Section of Gastroenterology and Hepatology, ${ }^{\ddagger}$ Department of Medicine, and the Graduate Program in Integrative Molecular and Biomedical Sciences, ${ }^{\S}$ Baylor College of Medicine, Houston, Texas; the Department of Pathology, ${ }^{\dagger}$ Texas Children's Hospital, Houston, Texas; and the Division of Digestive and Liver Diseases, ${ }^{\circledR}$ Department of Medicine and Irving Cancer Center, Columbia University, New York, New York
\end{abstract}

Accepted for publication June 21, 2017.

Address correspondence to James Versalovic, M.D., Ph.D. Department of Pathology, Texas Children's Hospital, Feigin Tower, 1102 Bates St., FC Ste. 830, Houston, TX 77030. E-mail: jamesv@ bcm.edu.

\begin{abstract}
Microbiome-mediated suppression of carcinogenesis may open new avenues for identification of therapeutic targets and prevention strategies in oncology. Histidine decarboxylase (HDC) deficiency has been shown to promote inflammation-associated colorectal cancer by accumulation of $\mathrm{CD} 11 \mathrm{~b}^{+} \mathrm{Gr}-1^{+}$immature myeloid cells, indicating a potential antitumorigenic effect of histamine. Here, we demonstrate that administration of $h d c^{+}$Lactobacillus reuter in the gut resulted in luminal $h d c$ gene expression and histamine production in the intestines of $\mathrm{Hdc}^{-/-}$mice. This histamine-producing probiotic decreased the number and size of colon tumors and colonic uptake of $\left[{ }^{18} \mathrm{~F}\right]$-fluorodeoxyglucose by positron emission tomography in $\mathrm{Hdc}^{-/-}$mice. Administration of $L$. reuteri suppressed keratinocyte chemoattractant $(K C), I L 22, I l 6$, Tnf, and IL1 $\alpha$ gene expression in the colonic mucosa and reduced the amounts of proinflammatory, cancer-associated cytokines, keratinocyte chemoattractant, IL-22, and IL-6, in plasma. Histamine-generating $L$. reuteri also decreased the relative numbers of splenic $\mathrm{CD} 11 \mathrm{~b}^{+} \mathrm{Gr}-1^{+}$immature myeloid cells. Furthermore, an isogenic $\mathrm{HDC}$-deficient L. reuteri mutant that was unable to generate histamine did not suppress carcinogenesis, indicating a significant role of the cometabolite, histamine, in suppression of chronic intestinal inflammation and colorectal tumorigenesis. These findings link luminal conversion of amino acids to biogenic amines by gut microbes and probiotic-mediated suppression of colorectal neoplasia. (Am J Pathol 2017, 187: 2323-2336; http://dx.doi.org/10.1016/j.ajpath.2017.06.011)
\end{abstract}

Colorectal cancer (CRC) is the third most common cancer and the third leading cause of cancer-related mortality. ${ }^{1}$ Population-based cohort studies have shown that patients with inflammatory bowel disease have an increased lifetime risk of CRC compared with the general population. ${ }^{2,3}$ This risk can be reduced by treatment of colitis with suppression of intestinal inflammation. ${ }^{4}$ These observations, in conjunction with studies showing that immune cells, cytokines, and other immunomodulatory agents play a role in CRC development, ${ }^{5}$ underline the association between CRC and colonic inflammation.

The role of the intestinal microbiome in colon cancer development has recently been investigated. ${ }^{6-9}$ Specific gut microbes and their metabolites may contribute to the cause of CRC. ${ }^{10-12}$ Manipulation of the gut microbiome by probiotics could provide new therapeutic strategies for CRC prevention. Several probiotic strains including Bifidobacterium longum, ${ }^{13}$ Lactobacillus acidophilus NCFM, ${ }^{14}$ and Lactobacillus rhamnosus $\mathrm{GG}^{15}$ have shown beneficial

\footnotetext{
Supported by the NIH (J.V.), including the National Institute of Diabetes, Digestive and Kidney Diseases grant R01 DK065075, Texas Medical Center Digestive Disease Center grant P30 DK56338, National Cancer Institute grant U01 CA170930, and unrestricted research support from BioGaia AB (J.V.).

Disclosures: J.V. receives unrestricted research support from Biogaia AB.

Current address of C.G., Immunology Research, Janssen Pharmaceutical Companies of Johnson \& Johnson, Spring House, PA.
} 
effects in different murine models of colon cancer. However, the molecular mechanisms mediating suppression of colonic carcinogenesis by these microbes remain unknown.

Lactobacillus reuteri is a commensal intestinal Firmicute and probiotic that is widely prevalent in the gastrointestinal tracts of diverse avian and mammalian species. ${ }^{16}$ L. reuteri has been reported to suppress production of proinflammatory cytokines by intestinal epithelial cells ${ }^{17}$ and monocytes,${ }^{18}$ in addition to reducing intestinal inflammation in different rodent models. ${ }^{17,19-23} \mathrm{~A}$ pangenomic study showed that human-derived clade II $L$. reuteri strains contained a complete chromosomal $h d c$ gene cluster (genes $h d c A, h d c B, h d c P$ ) and the genetic capacity to convert histidine to histamine. ${ }^{24}$ The ability to generate histamine by strains of this clade was correlated with suppression of human tumor necrosis factor (TNF) production. ${ }^{24}$ Studies also showed that histamine is considered to be a primary candidate immunomodulin produced by $L$. reuteri. ${ }^{18}$ Inactivation of histidine-to-histamine converting capacity by mutagenesis of the histidine decarboxylase gene $(h d c A)$ or the histidine-histamine antiporter gene $(h d c P)$ diminished the ability of $h d c$-positive $L$. reuteri strain ATCC (Manassas, VA) PTA 6475 to suppress human TNF production. ${ }^{18}$ Exploration of histidine metabolism, particularly histamine production by the gut microbes, deserves attention as a possible gateway to deepening our understanding of microbiome-mediated intestinal immunomodulation. ${ }^{25,26}$

The lack of functional mammalian histidine decarboxylase (HDC), the enzyme converting L-histidine to histamine, yielded increased susceptibility to inflammationassociated CRC in adult mice. ${ }^{27}$ Here, we set out to address the ability of $h d c^{+} L$. reuteri to reduce the frequency and severity of inflammation-associated colon cancer in $\mathrm{Hdc}^{-/-}$mice and to investigate whether microbe-generated metabolites may suppress inflammation-associated cancer phenotypes exacerbated by mammalian enzyme deficiencies.

\section{Materials and Methods}

\section{Association between HDC and H2R Gene Expression and Overall Survival Rates in Colon Cancer Patients}

To investigate whether HDC and histamine $\mathrm{H} 2$ receptor (H2R; symbol: HRH2) expression is associated with changes in survival rates of colon cancer patients, the PROGgeneV2 database ${ }^{28}$ was queried by selecting gene name HDC or HRH2, cancer type colorectal, and survival measure death. Samples were divided into high and low gene expression groups, bifurcating at median expression value for mRNA expression. Data were plotted and compared by using the Coxph function to compute hazard ratio estimate and related log-rank test $P$ value according to Goswami and Nakshatri. ${ }^{28}$ All of the CRC data sets in the database (2113 patient samples in 15 data sets) were included in this search (http://watson.compbio.iupui.edu/ chirayu/proggene/database/index.php, last accessed May 12, 2017).

\section{Bacterial Strains and Culture Conditions}

Bacterial strains, including L. reuteri ATCC PTA 6475 and its isogenic $h d c A$ mutant (generated by induction of a stop codon in $h d c A$ gene), were described previously. ${ }^{18}$ Both strains were cultured at $37^{\circ} \mathrm{C}$ in deMan, Rogosa, Sharpe (MRS) media (Difco, Franklin Lakes, NJ) in an anaerobic workstation (MACS MG-500; Microbiology International, Frederick, MD) supplied with a mixture of $10 \% \mathrm{CO}_{2}, 10 \%$ $\mathrm{H}_{2}$, and $80 \% \mathrm{~N}_{2}$.

\section{Mouse Care}

$H d c^{-/-}$BALB/c mice in which exon 5 of the $H d c$ gene was replaced with a neomycin cassette were originally provided by Timothy C. Wang (Columbia University, New York, NY) and rederived at Baylor College of Medicine (Houston, TX) by embryo transfer. Four pups, including two male and two female pups, were obtained from rederivation. Mouse tail clippings were used for mouse DNA extraction. The Hdcdeficient genotype of the rederived mice was confirmed by PCR and DNA gel electrophoresis, with neomycin amplicon primers (forward, 5'-AATGGCCGCTTTTCTGGATTCA3'; reverse, 5'-GGGAGCGGCGATACCGTAAAG-3') and exon 5 of $H d c$ gene amplicon primers (forward, $5^{\prime}$ TTAGTCTTTGGGTGTTCCTGGTCA-3'; reverse, $5^{\prime}$ CCCTGTTGCTTGTCTTCCTCAATA- ${ }^{\prime}$ ). Breeding and maintenance of $\mathrm{Hdc}^{-/-}$mice were performed under specific pathogen-free conditions at Texas Children's Hospital (Houston, TX). Mice were kept under filter top cages and had free access to distilled water and PicoLab Rodent 50IF/6F diet. All mouse experiments were performed according to an Institutional Animal Care and Use Committee-approved mouse protocol at Baylor College of Medicine.

\section{Bacterial Preparation and Administration to Mice}

L. reuteri was cultured in MRS media, and bacteria were harvested at exponential phase. Cells were centrifuged at $2500 \times g$ for 4 minutes, and the bacterial pellets were resuspended in sterile MRS media for animal feeding. L. reuteri strains were freshly prepared before administration to mice. Each mouse received $5 \times 10^{9}$ colony-forming units of bacteria in $0.2 \mathrm{~mL}$ of MRS media or MRS media only as control by orogastric gavage. The frequency of bacteria administration was once per day for 7 days before azoxymethane (AOM; Sigma-Aldrich, St. Louis, MO) injection, followed by administration once per 3 days for 15 weeks. L. reuteri was not administered during the two cycles of dextran sulfate sodium (DSS; 36,000 to 50,000 molecular weight; MP Biomedicals, Solon, $\mathrm{OH}$ ) challenge in drinking water (6 days per cycle). 


\section{Induction of Colon Cancer in BALB/C Mice}

At 12 weeks of age, mice in the positive control group and bacteria-treated groups received a single dose of the genotoxic colonic carcinogen AOM (12.5 mg/kg body weight) by i.p. injection. These mice were challenged with two cycles of 2\% (w/v) DSS in drinking water for 6 days, with one cycle immediately after AOM injection, followed by a recovery period with drinking water for 2 weeks before the second cycle. Mice in the negative control group received one dose of phosphate-buffered saline (PBS) solution instead of AOM and drinking water.

\section{Tumor Assessment and Tissue Preparations}

Fifteen weeks after AOM injection, mice were euthanized, and specimens were collected as follows. Blood was collected from sedated mice via cardiac puncture in blood sample collection tubes with $\mathrm{K}_{2}$ EDTA (Becton, Dickinson and Company, Franklin Lakes, NJ) and centrifuged at $17,000 \times g$ for 10 minutes at $4^{\circ} \mathrm{C}$ to isolate plasma. The gastrointestinal tract was carefully removed, and luminal contents of ileum, cecum, and colon were collected and flash-frozen in liquid nitrogen. The mouse colons were excised and opened longitudinally, and the number and size of tumors were counted and measured blindly (M.L.). Intestinal mucosa was scraped with an operating knife blade and stored in RNALater (Ambion, Austin, TX) to analyze cytokine mRNA expression. All of the samples were stored at $-80^{\circ} \mathrm{C}$ until analyzed.

Mouse intestines were fixed in $10 \%$ formalin, embedded with paraffin, and sectioned at $3 \mu \mathrm{m}$ by a microtome. Hematoxylin and eosin staining was performed.

\section{Flow Cytometric Analysis}

Bone marrow and spleen samples were collected immediately after euthanasia of mice. Bone marrow-derived cells from the femurs and tibia were immediately flushed with icecold Dulbecco's modified Eagle's medium (ATCC) containing $10 \%$ fetal bovine serum. This procedure was followed by the addition of red blood cell lysis buffer to deplete red blood cells (BD Biosciences, San Jose, CA). Spleen samples were stored in ice-cold Dulbecco's modified Eagle's medium with $10 \%$ fetal bovine serum. This step was followed by the isolation of the spleen cells using sterile glass slides and addition of red blood cell lysis buffer to the isolated cells. Single-cell suspensions were made by filtering the cells through $40-\mu \mathrm{m}$ filter strains. For flow cytometric analysis, single-cell suspensions were stained with antibodies $[1 \mu \mathrm{L}$ of allophycocyanin-cyanine 7-conjugated anti-Gr-1 (BD Biosciences), and $5 \mu \mathrm{L}$ of fluorescein isothiocyanate-conjugated anti-CD11b (BD Biosciences)] for 30 minutes on ice, in the dark and evaluated by multicolor flow cytometry using a BD FACSCanto cell analyzer and data collected with FACSDiva software version 6
(BD Biosciences). The accumulated data were analyzed with FlowJo software version 10 (FlowJo, Ashland, OR) gated using forward scatter and side scatter, followed by allophycocyanin-cyanine $7\left(\mathrm{Gr}-1^{+}\right)$on the $y$ axis and fluorescein isothiocyanate $\left(\mathrm{CD} 11 \mathrm{~b}^{+}\right)$on the $x$ axis.

\section{PET Imaging of Living Mice}

Positron emission tomography (PET)/computed tomography (CT) scanning was performed 15 weeks after AOM injection, just before euthanizing the mice as described previously. ${ }^{23}$ Briefly, mice were anesthetized with isoflurane and received $200 \mu \mathrm{Ci}$ of ${ }^{18} \mathrm{~F}$-fluorodeoxyglucose (FDG) by i.p. injection. After 1 hour, these mice received $200 \mu \mathrm{L}$ of MDGastroview as contrast agent rectally via a $3.5 \mathrm{~F}$ catheter. CT scan was performed for 10 minutes, followed by a PET scan for 20 minutes using the Inveon PET/CT Multimodality System (Siemens, Munich, Germany). Mouse images were recorded, and FDG standardized uptake values were analyzed blindly (R.R.S.) using Inveon Research Workplace software version 1.5 (Siemens). The images of mice were generated by OsiriX Imaging software version 3.9.4 (Pixmeo, Bernex, Switzerland).

\section{Determination of the Relative Abundances of $L$. reuteri, hdc Genes, and mRNA in Vivo}

Twelve-week-old male $H d c^{-/-}$mice were given one dose of L. reuteri 6475 or $h d c A$ mutant or MRS media only as described above. After 2 days, the mice were euthanized, and total DNA and RNA from luminal contents in the distal colon were isolated for bacterial DNA and mRNA extraction. Relative bacterial DNA and mRNA quantities of $h d c$ genes were evaluated by real-time quantitative PCR and normalized to the housekeeping gene $r p o B$ as described previously. ${ }^{23}$ Whole colons were fixed in Carnoy's solution, and fluorescence in situ hybridization was performed with a probe specific to a unique $16 \mathrm{~S}$ rRNA sequence to $L$. reuteri (Reverse: $\quad 5^{\prime}$-GATCCATCGTCAATCAGGTGC-3') as described previously. ${ }^{29}$ Slides were counterstained with DAPI (Sigma-Aldrich) and imaged at $\times 400$ magnification with an Eclipse 90i fluorescence microscope (Nikon Instruments, Melville, NY).

\section{Histamine Quantification in $\mathrm{Hdc}^{-/-}$Mouse Feces}

Fecal specimens were weighed and dissolved in $200 \mu \mathrm{L}$ of $50 / 50 \mathrm{PBS} /$ methanol by vortexing and ultrasound disruption for 4 minutes with 30-second intervals. After spinning for 5 minutes, $14,000 \times g$ at $4^{\circ} \mathrm{C}$, the supernatant fluids were size-fractionated with Amicon Ultra- $0.5 \mathrm{~mL}$ centrifugal filters (molecular weight cutoff, $3 \mathrm{kDa}$; Millipore, Temecula, CA). The histamine quantities in the collected supernatant fluids were determined by liquid chromatography-mass spectrometry using selected reaction monitoring (SRM). 
Table 1 Primers Used in qPCR-Based Gene Expression Studies

\begin{tabular}{|c|c|}
\hline $\begin{array}{l}\text { Gene/ } \\
\text { primer } \\
\text { name }\end{array}$ & Primer pairs \\
\hline \multirow[t]{2}{*}{$I l 1 \alpha$} & F: 5'-CAGAGAGGGAGTCAACTCATTG-3' \\
\hline & R: 5'-GTTTCTGGCAACTCCTTCAGC-3' \\
\hline \multirow[t]{2}{*}{ KC } & F: 5'-GACTCCAGCCACACTCCAAC- $3^{\prime}$ \\
\hline & R: 5'-TGACAGCGCAGCTCATTG-3' \\
\hline \multirow[t]{2}{*}{ Il22 } & F: 5'-TGACGACCAGAACATCCAGA-3' \\
\hline & R: 5'-AATCGCCTTGATCTCTCCAC-3' \\
\hline \multirow[t]{2}{*}{ Ifn- $\gamma$} & F: 5'-GCCAAGTTTGAGGTCAACAACCC-3' \\
\hline & R: 5'-CCGAATCAGCAGCGACTCCT-3' \\
\hline \multirow[t]{2}{*}{$\operatorname{Tnf}$} & F: 5'-ССТСАСАСТСАGАTСАТСТTСТС-3' \\
\hline & R: 5'-GTCTTTGAGATCCATGCCGT-3' \\
\hline \multirow[t]{2}{*}{ Il6 } & F: 5'-CTCTGCAAGAGACTTCCATCCA-3' \\
\hline & R: 5'-TAAGCCTCCGACTTGTGAAGTA-3' \\
\hline \multirow[t]{2}{*}{ Il12 } & F: 5'-ATGTGTCAATCACGCTACСTCCTC-3' \\
\hline & R: 5'-GGTCTTCAGCAGGTTTCGGG-3' \\
\hline \multirow[t]{2}{*}{ Il23 } & F: $5^{\prime}-$ TAGCCTGGAACGCACATGCAC-3' \\
\hline & R: 5'-GCAAGCAGAACTGGCTGTTGTA-3' \\
\hline \multirow[t]{2}{*}{ Il17 } & F: 5'-ACTCTCCACCGCAATGAAGACA-3' \\
\hline & R: 5'-CCCTCTTCAGGACCAGGATCTC-3' \\
\hline \multirow[t]{2}{*}{ Gapdh } & F: 5'-GCCAAAAGGGTCATCATCTC-3' \\
\hline & R: 5'-CACACCCATCACAAACATGG-3' \\
\hline \multirow[t]{2}{*}{$h d c A$} & F: 5'-GCACTAACGATAACCGTCGTC-3' \\
\hline & R: 5'-CACCCTTATTAGCACAAACAATGA-3' \\
\hline \multirow[t]{2}{*}{$h d c P$} & F: 5'-TCCCTACGGATACCAAGCAC-3' \\
\hline & R: 5'-AGAGGAACGCTAAGACACCAAT- $3^{\prime}$ \\
\hline \multirow[t]{2}{*}{$r p o B$} & F: 5'-CGTGATACTTCATTACGTGTTCCT-3' \\
\hline & R: 5'-AGTGAAGACTTTAACATCTTGGATGA-3' \\
\hline
\end{tabular}

$\mathrm{KC}$, keratinocyte chemoattractant; $\mathrm{qPCR}$, real-time quantitative $\mathrm{PCR}$.

For histamine quantification, $30 \mu \mathrm{L}$ of each sample was dried in a SpeedVac for 2 hours. The dried samples were mixed with $30 \mu \mathrm{L}$ of $20 \mathrm{ng} / \mathrm{mL}$ histamine-d4 (histamine$\alpha, \alpha, \beta, \beta-\mathrm{d} 4$; CDN Isotopes, Pointe-Claire, Canada) solution by vortexing for 1 minute. The prepared samples were loaded into a Shimadzu (Kyoto, Japan) SIL-20ACxr autosampler and separation was achieved using a Shimadzu Nexera-XR HPLC system. Samples $(5 \mu \mathrm{L})$ were loaded onto a Phenomenex (Torrance, CA) $1 \mathrm{~mm} \times 50 \mathrm{~mm}$ phenylhexyl reversed phased column equipped with a Phenomenex phenylhexyl $4 \mathrm{~mm} \times 2 \mathrm{~mm}$ guard column. The aqueous mobile phase (A) consisted of water/acetonitrile/ formic acid/perfluoroheptanoic acid (99.3:0.5:0.1:0.1 v/v/v/ $\mathrm{v})$, and the organic mobile phase (B) consisted of acetonitrile/formic acid (99.9:0.1 v/v). Column flow was set at 80 $\mu \mathrm{L} /$ minute. The elution gradient was optimized as follows: started from $20 \%$ B for 0.5 minute and increased to $70 \% \mathrm{~B}$ over 5.5 minutes; ramp to $80 \% \mathrm{~B}$ after 0.1 minute and hold for 1 minute; ramp back to $20 \% \mathrm{~B}$ over 6 seconds and maintained at $20 \%$ for a total chromatographic run time of 12 minutes to re-equilibrate.

SRM was performed on a Sciex (Framingham, MA) 6500 QTRAP mass spectrometer equipped with a Turbo $\mathrm{V}$ ion source. The mass spectrometer was operated in the positive ion mode under the following conditions: curtain gas of 20 psi; collision gas, High; spray voltage, $4.5 \mathrm{kV}$; ion source gas 1, 20 psi; ion source gas 20, 2 psi; interface heater temperature, $175^{\circ} \mathrm{C}$; Q1 and Q3 resolution, unit; scan time, 100 milliseconds; de-clustering potential, $100 \mathrm{~V}$; entrance potential, $8 \mathrm{~V}$; and collision exit potential, $10 \mathrm{~V}$. The instrument was calibrated by using Sciex PPG calibration standard and tuned to the manufacturer's specifications. SRM transitions monitored for histamine were $112 \rightarrow 95$ $(20 \mathrm{eV})$ and $112 \rightarrow 68(30 \mathrm{eV})$. For histamine-d4, the SRM transitions $116 \rightarrow 99(20 \mathrm{eV})$ and $116 \rightarrow 72(30 \mathrm{eV})$ were monitored. Data were acquired with Analyst Software version 1.6.2 (AB Sciex LP, Concord, ON, Canada) and quantification performed using Multiquant Software version 3.0.1 (AB Sciex LP).

\section{Cytokine Measurement by Multiplex Immunoassay in the Mouse Plasma}

The concentrations of murine interferon (Ifn)- $\gamma$, Il- $1 \alpha$, Il-1 $\beta$, Il-4, Il-6, Il-10, Il-12, Il-13, Il-17A, keratinocyte chemoattractant (KC), Tnf, Il-21, Il-22, Il-23, and epidermal growth factor in the plasma were measured using cytokine multiplex kits (Millipore, Billerica, MA). Quantification of cytokines was performed using the Luminex system (Austin, TX) according to the manufacturer's instructions. Briefly, 25- $\mu \mathrm{L}$ plasma samples collected above from each mouse were thawed completely and diluted with the same amount of Assay Buffer provided in the kits. The assays were performed in duplicate blindly (S.V.). The reports automatically generated by MILLIPLEX Analyst software version 5.1 (Millipore) were reviewed, and only cytokines that were greater than the lower limit of detection and below the saturation value were considered.

\section{Modulation of Mammalian Cytokine Gene Expression in the Colonic Mucosa}

To quantify the relative mRNA expression levels of Ifn- $\gamma$, Tnf, Il-6, Il-12, Il-23, Il-17, Il-22, Il-1 $\alpha$, and KC, RNA was extracted from colonic mucosa samples using the miRNeasy mini kit (Qiagen, Hilden, Germany). One microgram of RNA was reverse-transcribed to single-stranded cDNA using the RevertAid H minus First Strand cDNA Synthesis Kit (ThermoFisher Scientific, Waltham, MA). Real-time RT-PCR was performed using Real-Time PCR system (Stratagene, La Jolla, CA). The RT-PCR reaction mix (adjusted with water to a total volume of $25 \mu \mathrm{L}$ ) contained $1 \mu \mathrm{L}$ of template DNA, $12.5 \mu \mathrm{L}$ of Power SYBR Green PCR master mix (ABI, Life Technologies, Carlsbad, CA), and $0.5 \mu \mathrm{L}$ of the respective primers $(10 \mu \mathrm{mol} / \mathrm{L}$ each $)$. The primers used for IFN- $\gamma$, IL-12, IL-17, TNF, IL-6, and IL-23 quantification were described previously, ${ }^{30}$ and all of the primers are shown in Table 1. Relative murine mRNA target gene expression levels (Ratio $=\left[\left(\mathrm{E}_{\text {target }}\right)^{\mathrm{dCP} \text { target }}\right.$ (Control-Sample) $] /$ $\left.\left[\left(\mathrm{E}_{\mathrm{ref}}\right)^{\text {dCPref. (Control-Sample) }}\right]\right)$ were normalized to the housekeeping gene GAPDH and used as a reference. Subsequently, 

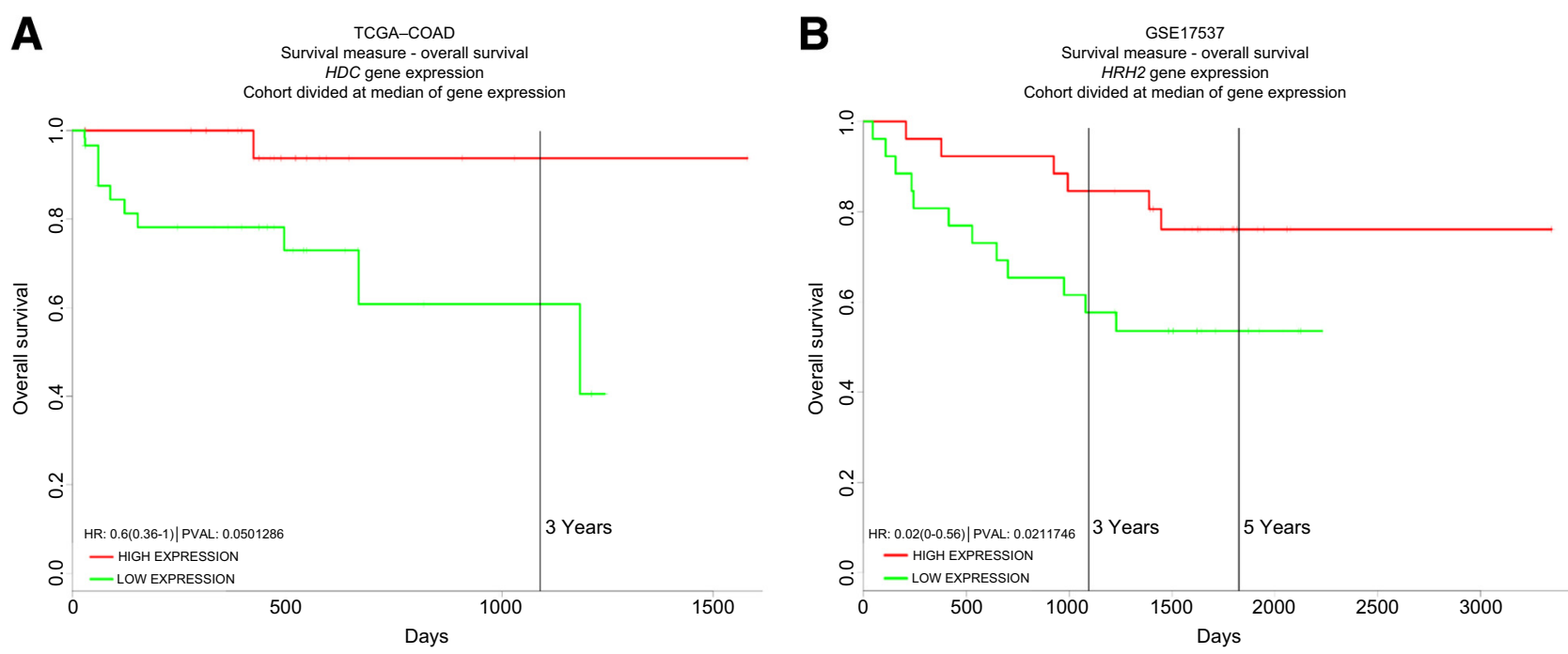

Figure 1 Overall survival rates increase in colon cancer patients with elevated human $H D C$ and $H R H 2$ gene expression. The overall survival rates in colorectal cancer patients based on HDC or HRH2 gene expression categories were plotted using the PROGgeneV2 database. Representative figures with the lowest $P$ value are shown for HDC (A) and HRH2 (B). HR, hazard ratio; PVAL, $P$ value.

intestinal mucosal cytokine gene expression values of the control group were set to 1.0 and used as the calibrator to identify the relative mRNA fold difference between the negative control group (MRS/PBS- $\mathrm{H}_{2} \mathrm{O}$ ), positive control group (MRS/AOM-DSS), L. reuteri 6475-treated group $(L$. reuteri 6475/AOM-DSS), and isogenic L. reuteri hdcA mutant-treated group ( $h d c A$ mutant/AOM-DSS).

\section{Statistical Analysis}

Statistical analysis was performed using GraphPad Prism software version 5 (GraphPad Inc., La Jolla, CA). For numeric variables that fit normal distribution (determined by Kolmogorov-Smirnov test), data were presented as means $\pm \mathrm{SD}$, and different groups were compared with the $t$-test (two groups) or one-way analysis of variance (more than two groups). Otherwise, data were presented as box and whiskers plots showing the median values and 10th and 90th percentiles or scatter plots showing the median values. Different groups were compared by a nonparametric $U$-test (two groups) or Kruskal-Wallis test.

\section{Results}

Elevated Human HDC and H2R Gene Expression Are Associated with Improved Survival Outcomes in Colon Cancer Patients

HDC is the key enzyme involved in histidine-to-histamine conversion and histamine generation in mammalian and bacterial cells. To investigate the association between $H D C$ gene expression and survival rates in CRC patients, a large-scale human cancer gene expression database named PROGgene ${ }^{28}$ was explored. Patients with elevated patterns of $H D C$ gene expression demonstrated improved survival in CRC (TCGA_COAD; $P=0.05$ ) (Figure 1A).

We further investigated the association between $\mathrm{H} 2 \mathrm{R}$ gene expression and survival rates in CRC patients because our previous study ${ }^{23}$ indicated an H2R-mediated suppression of colitis by histamine. Elevated patterns of H2R gene (HRH2) expression was correlated with enhanced survival among patients with CRC (GSE17537; $P=0.02$ ) (Figure 1B), indicating a potential antitumorigenic effect by H2R up-regulation.

These findings based on human cancer gene expression profiling set the stage to explore whether microbial Hdc expression and histamine generation could complement histamine deficiency in $\mathrm{Hdc}^{-/-}$mice and provide mechanistic insights in murine models of CRC.

\section{L. reuteri 6475 Administration Increases hdc Gene Expression and Histamine Production in the Intestines of $\mathrm{Hdc}^{-/-}$Mice}

To explore whether oral administration of $L$. reuteri increased the relative abundance of this bacterial species in the intestines of $\mathrm{Hdc}$-deficient mice, fluorescence in situ hybridization was performed in the colons of $\mathrm{Hdc}^{-1-}$ mice 2 days after $L$. reuteri administration. Orogastric gavage with wild-type $L$. reuteri 6475 and $\mathrm{HdcA}$-deficient $L$. reuteri increased the relative abundances of $L$. reuteri in the colonic lumen visualized by fluorescence microscopy compared with control mice that did not receive exogenous bacteria (Figure 2A). In addition, the relative abundances of $h d c A$ DNA and hdcA and hdcP mRNA were significantly increased, demonstrating active gene expression in the intestinal lumen by viable bacteria (Figure 2, B-D). 
A

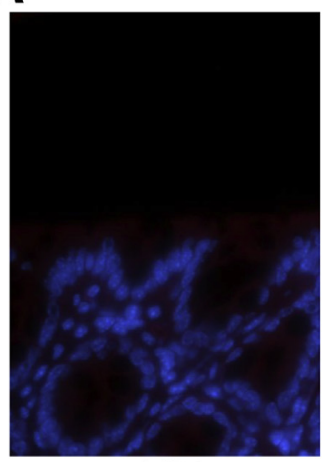

MRS

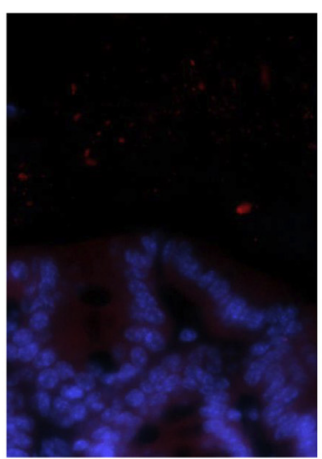

L. reuteri 6475

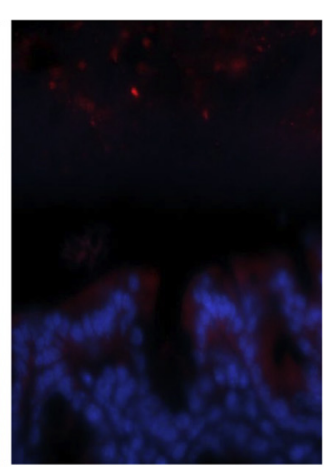

hdcA mutant
B

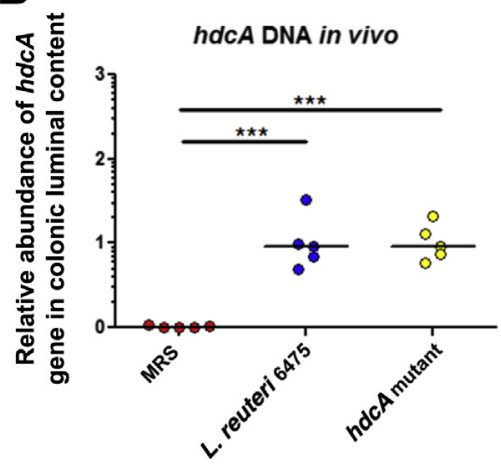

$\mathbf{E}$

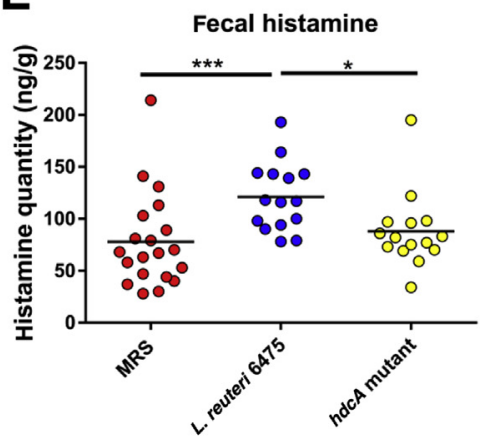

Figure 2 Increased abundance of bacterial histidine decarboxylase ( $\mathrm{Hdc}$ ) mRNA and histamine in the mouse intestine after Lactobacillus reuteri supplementation. A: Representative figures showing the microscopic visualization of $L$. reuteri in the colon of $H_{d c^{-}}{ }^{-}$mice. Media only, L. reuteri 6475 , or HdcA-deficient $L$. reuteri were administered to mice orally, followed by $L$. reuteri species-specific fluorescence in situ hybridization after 2 days. Red indicates cyanine 3-conjugated probe to label $L$. reuteri; blue, DAPI-labeled host cell nuclei. B: Relative abundance of $h d c A$ gene in mouse gut microbiome in different groups. C and D: Relative quantities of hdcA (C) and hdcP (D) mRNA in colonic luminal contents of mice. E: Histamine quantities in mouse feces determined by liquid chromatography-mass spectrometry. $n=5$ for each group (A-D); $n=15$ to 20 for each group (E). ${ }^{*} P<0.05, * * * P<0.001$. MRS, deMan, Rogosa, Sharpe.

Moreover, L. reuteri 6475 administration significantly increased histamine quantities in mouse feces, in contrast to the lack of increased amounts of histamine after administration of $L$. reuteri defective in HDC function ( $h d c A$ mutant) (Figure 2E). These studies indicate that i) L. reuteri administration increased its relative abundance in the guts of $H d c^{-1-}$ mice, and the presence of $L$. reuteri in the intestine was not affected by the presence or absence of an intact HCD gene in L. reuteri; ii) L. reuteri can express the HCD and histidine/histamine antiporter genes in the mammalian intestines of $H d c^{--}$mice; iii) $h d c$-positive L. reuteri is able to generate histamine in the gut, providing a mechanistic underpinning for histamine-mediated immunomodulation by the mammalian gut microbes.

\section{HDC Gene Is Necessary for $L$. reuteri 6475 to Attenuate Colonic Carcinogenesis in Vivo}

To probe the ability of histamine-generating L. reuteri 6475 to suppress CRC associated with chronic intestinal inflammation, the combination of AOM and DSS was used to induce colitis-associated colon cancer in 12-week-old male $H d c^{-1-}$ BALB/c mice (Figure 3A). We found that negative control mice that received PBS and drinking water, instead of AOM and 2\% DSS, did not develop tumors (Figure 3, $\mathrm{B}-\mathrm{E})$. Positive control mice that were challenged with AOM/DSS and gavaged with MRS media, but did not receive exogenous bacteria, developed colonic tumors. Administration of exponential phase L. reuteri 6475 with a wild-type allele of the HDC gene significantly reduced the number and size of colonic tumors in male mice compared with the positive control group. However, oral administration of Hdc-deficient $L$. reuteri did not suppress colonic carcinogenesis. The relative abundances of $h d c A$ DNA and $h d c A$ and $h d c P$ mRNA in the feces of the experimental mice were also determined (Supplemental Figure S1), and these bacterial genes showed a similar pattern as luminal contents (Figure 2, B-D), indicating that AOM and DSS did not affect L-histidine metabolism by $L$. reuteri.

\section{Abdominal Imaging Yields Evidence of Suppression of Colon Tumorigenesis by $L$. reuteri}

To further confirm the antitumorigenic effects of $L$. reuteri in the AOM/DSS-induced Hdc-deficient mouse model of colon cancer, PET imaging was applied to evaluate the 
A

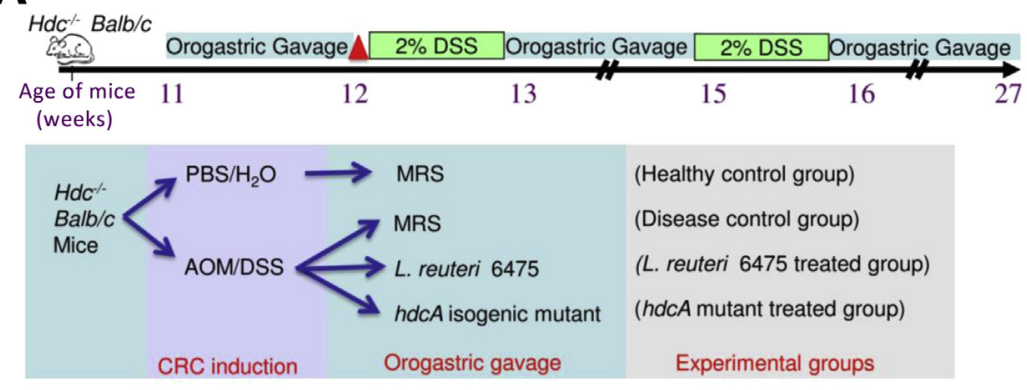

$\triangle$ AOM injection $\square$ DSS treatment

C

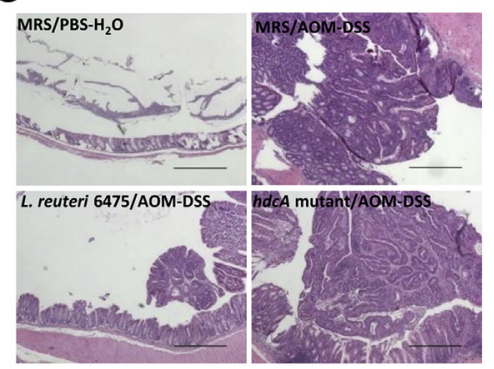

B

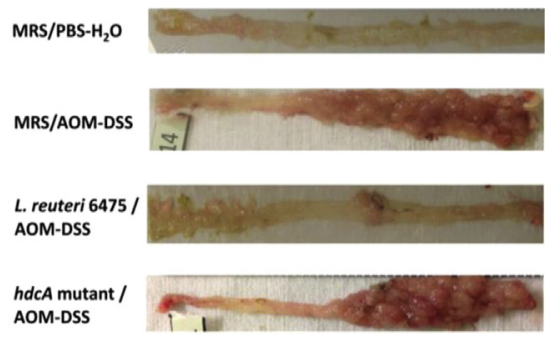

$\mathbf{E}$

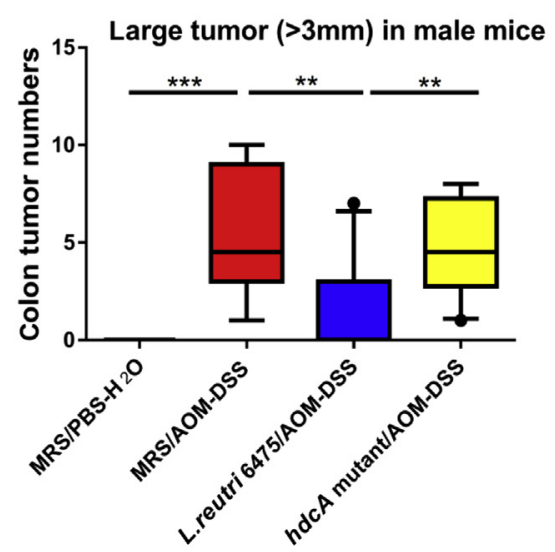

Small tumor $(<3 \mathrm{~mm})$ in male mice



Figure 3 Lactobacillus reuteri 6475 but not the $h d c A$ mutant attenuates colonic carcinogenesis in vivo. A: Procedures for mouse experiments. B: Representative colon images of mice in the negative control group [deMan, Rogosa, Sharpe/phosphate-buffered saline-water (MRS/PBS- $\left.\mathrm{H}_{2} 0\right)$ ], positive control group [MRS/azoxymethane-dextran sulfate sodium (AOM-DSS)], L. reuteri 6475-treated group (L. reuteri 6475/A0M-DSS), and isogenic L. reuteri hdcA mutant-treated group ( $h d c A$ mutant/AOM-DSS). C: Representative microscopic colon images (hemoxylin and eosin stained) from mice in different groups. D and E: Numbers of both large $(>3 \mathrm{~mm})$ and small $(<3 \mathrm{~mm})$ colonic tumors from mice in different groups. $n=8$ to 10 for each group $(\mathbf{D}$ and $\mathbf{E})$. ${ }^{* *} P<0.01$, $* * * P<0.001$. Scale bars $=500 \mu \mathrm{m}(\mathbf{C})$.

process of colonic carcinogenesis and suppression of colonic neoplasia in living mice before euthanasia (Figure 4A). Trace amounts of FDG signal were evident in the colon and surrounding abdominal sites, indicating low baseline glucose uptake in the colons of healthy mice (Figure 4, B and C, and Supplemental Video S1). In positive control mice, hot spots in the colon were observed, and the relative FDG intensity in the whole mouse colon was significantly increased compared with the negative control group (Figure 4, B and C, and Supplemental Video S2), indicating the presence of colonic tumors and increased glucose uptake in the colons of mice that received AOM plus DSS. L. reuteri 6475-treated mice showed reduced numbers of hot spots in the colon and significantly decreased abdominal FDG intensities compared with positive control mice, indicating that histamine-generating strain L. reuteri 6475 could suppress metabolic activity associated with colon carcinogenesis in live animals (Figure 4, B and C, and Supplemental Video S3). Meanwhile, the isogenic $h d c A$ mutant strain deficient in HDC activity did not yield similar effects and showed increased numbers of hot spots and increased abdominal FDG intensities compared with the wild-type strain and consistent with unfettered colon carcinogenesis (Figure 4, B and C, and Supplemental Video S4). Together, these results showed that histamine-generating lactobacilli could suppress carcinogenesis by interkingdom complementation, whereas isogenic strains incapable of generating histamine did not suppress colonic carcinogenesis.

\section{Histamine-Generating $L$. reuteri Suppresses Proinflammatory Cytokine Gene Expression in the Colonic Mucosa}

Specific proinflammatory cytokines have been reported to contribute to the development of colon tumorigenesis by promoting the formation of a tumor-supportive microenvironment. ${ }^{31}$ By analyzing cytokine gene expression of selected cytokines in the colonic mucosa (Table 1), we showed that AOM/DSS challenge induced expression of proinflammatory cytokine genes encoding KC, Il-22, Il-6, Tnf, and Il-1 $\alpha$ compared with healthy $\mathrm{Hdc}^{-/-}$mice (Figure 5). Oral treatment of AOM/DSS-challenged mice with $h d c$-positive $L$. reuteri 6475 reduced the relative gene expression of these cytokines, 

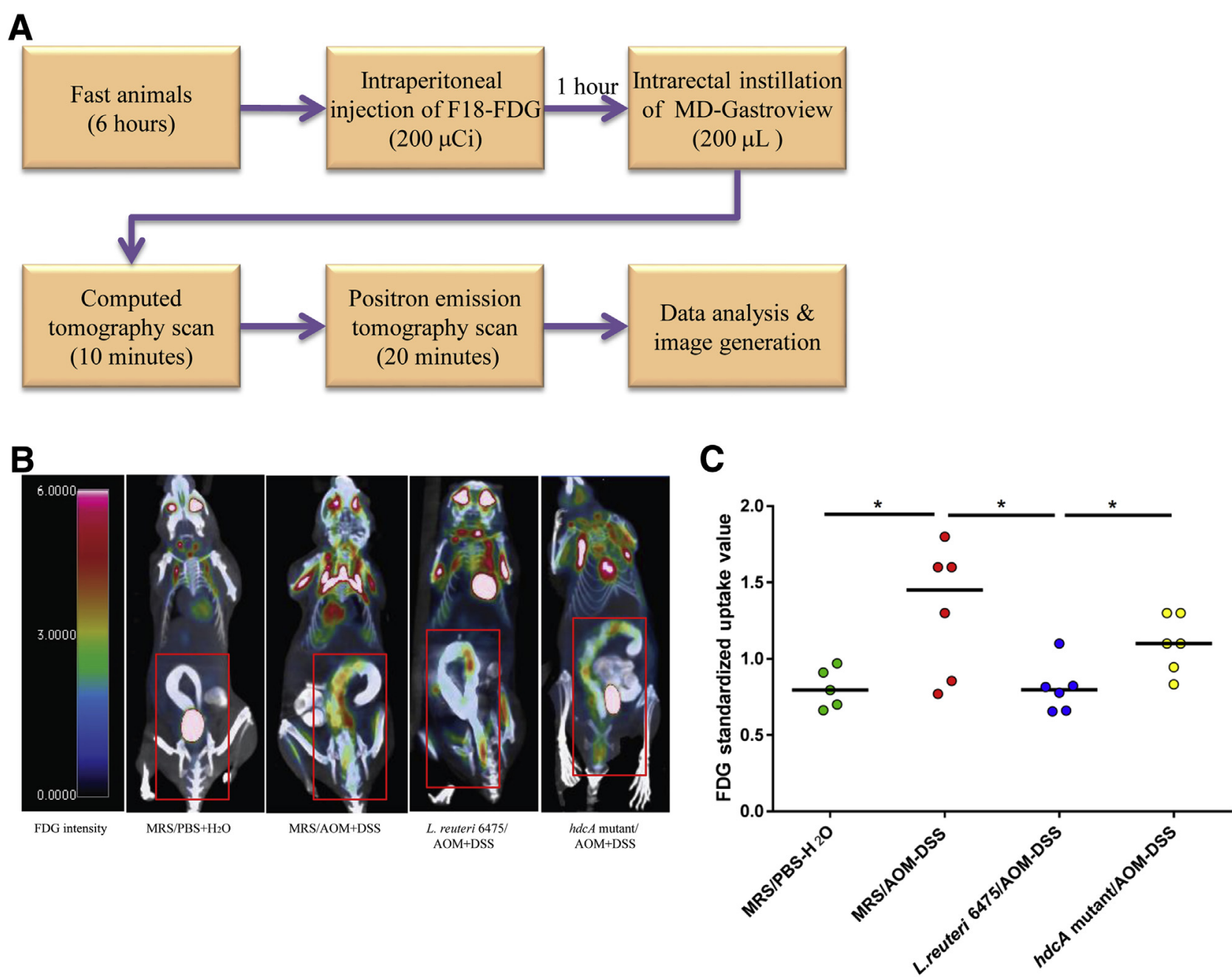

Figure 4 Attenuation of colonic tumorigenesis as shown by positron emission tomography (PET) imaging. A: A schematic diagram shows the PET imaging procedures with live mice. B: Representative mouse images captured by PET-computed tomography (CT) scanning in each group. The color code bar represents fluorodeoxyglucose (FDG) signal intensity. The abdominal regions are indicated with red boxes. C: Standardized uptake values of FDG signal in the whole mouse colon in different groups. $n=5$ to 6 for each group (B and C). ${ }^{*} P<0.05$. A0M, azoxymethane; DSS, dextran sulfate sodium; L. reuteri, Lactobacillus reuteri; MRS, deMan, Rogosa, Sharpe; PBS, phosphate-buffered saline.

whereas the isogenic L. reuteri strain lacking functional $\mathrm{HdcA}$ did not inhibit gene expression of these proinflammatory cytokines. Detection of other cytokine mRNAs by real-time quantitative PCR yielded either undetectable results (IL-17) or no significant differences (Il-12, Il-23, and Ifn- $\gamma$ ) among the groups (ie, cytokines that this probiotic intervention did not repress), indicating that histamine-generating $L$. reuteri suppressed a subset of proinflammatory murine cytokine genes in the colonic mucosa.

\section{Circulating Cytokine Concentrations in Plasma Are Reduced by Histamine-Generating $L$. reuteri}

To further investigate the association between cytokines and $\mathrm{CRC}$, we performed multiplex analyses of 16 cytokines (Supplemental Table S1) in the plasma by using a Luminex system (Millipore). AOM/DSS treatment in $H d c^{-/}$mice increased the relative concentrations of $\mathrm{KC}$,
Il-22, and Il-6 in plasma, compared with that of control mice (Figure 6). L. reuteri 6475 administration diminished concentrations of these three cytokines (KC, Il-22, Il-6), whereas administration of isogenic $L$. reuteri $h d c A$ mutant lacking histamine-producing capacity did not reduce these same cytokine concentrations in AOM/DSS-treated $\mathrm{Hdc}^{-1}$ - mice. The results with KC, Il-22, and Il-6 are consistent in terms of plasma protein quantitation and mucosal gene expression. Other cytokines measured in plasma were either not detectable (Il-1 $\beta$, Il-21, Il-23, epidermal growth factor) or showed no significant changes (Il-4, Il-17, Ifn, Il-1 $\alpha$, Il-12, Tnf, Il-10, Il-13) among groups, indicating selective reduction of circulating cytokines in plasma by histamine-generating $L$. reuteri. Together with cytokine gene expression in the colonic mucosa, histamine generation by lactobacilli appeared to be important for suppression of particular proinflammatory and cancerassociated cytokines. 


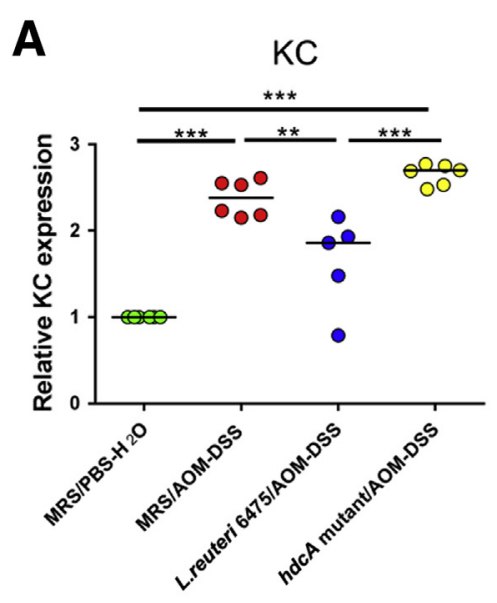

D

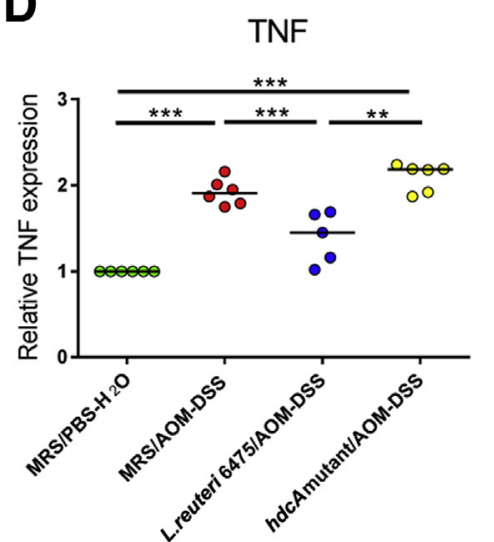

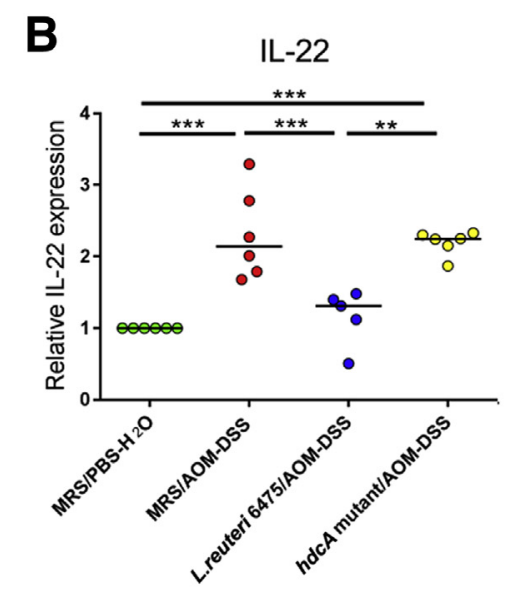

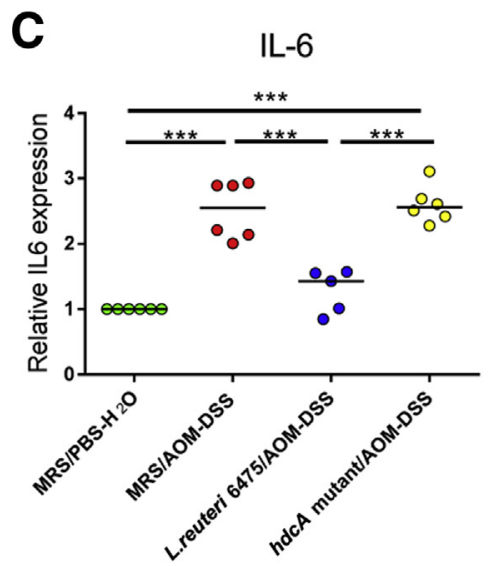

Figure 5 Histamine-generating Lactobacillus reuteri suppresses mammalian cytokine gene expression in colonic mucosa. Wild-type L. reuteri 6475 administration significantly decreases proinflammatory cytokine keratinocyte chemoattractant (KC) (A), IL-22 (B), IL-6 (C), tumor necrosis factor (Tnf) (D), and $\mathrm{Il}-1 \alpha(\mathbf{E})$ expression in $\mathrm{Hdc}^{-1-}$ mouse colonic mucosa in mRNA level determined by quantitative RT-PCR, whereas the isogenic $L$. reuteri hdcA mutant which lacks the histamine-producing capacity lacks such effects. ${ }^{*} P<0.05,{ }^{* *} P<0.01$, and ${ }^{* *} P<0.001$. A0M, azoxymethane; DSS, dextran sulfate sodium; MRS, deMan, Rogosa, Sharpe; PBS, phosphate-buffered saline.

\section{Abundance of Splenic Immature Myeloid Cells Is Suppressed by $h d c^{+}$L. reuteri}

The absence of endogenous histamine leads to markedly increased numbers of immature myeloid cells (IMCs; $\mathrm{CD}_{1} \mathrm{~b}^{+} \mathrm{Gr}-1^{+}$) after AOM/DSS treatment, and this finding is associated with cancer progression in mammals. ${ }^{27}$ Here, we found that the percentage of CD $11 b^{+} \mathrm{Gr}-$ $1^{+}$IMCs in the spleen was significantly increased in AOM/ DSS-challenged mice compared with healthy control mice (Figure 7, B and C), consistent with a previous report. ${ }^{27} L$. reuteri 6475 administration in AOM/DSS-challenged mice significantly decreased the relative abundance of $\mathrm{CD} 11 \mathrm{~b}^{+} \mathrm{Gr}-1^{+}$IMCs compared with mice that did not receive exogenous lactobacilli. A similar, although less dramatic pattern, was observed in the bone marrow (Figure 7, A and C). These observations are consistent with the conclusion that histamine-generating probiotic L. reuteri 6475 may attenuate AOM/DSS-induced colon carcinogenesis, at least in part, via enhanced maturation of circulating myeloid cells and concomitant reduction of proinflammatory cytokines produced by relatively mature myeloid cells.

\section{Discussion}

Histamine generated by intestinal microbes may supplement histamine-generating capacity by mammalian cells and may offer new possibilities for microbiome-mediated gene therapy. Our prior studies showed that microbial histamine may suppress intestinal inflammation in an acute colitis model. ${ }^{23}$ From the studies by Yang et $\mathrm{al}^{27}$ that showed an increased susceptibility of $\mathrm{Hdc}^{-/-}$mice to inflammation-associated colonic cancer induced by AOM/DSS challenge, we addressed the ability of histamine-producing gut microbes such as $L$. reuteri to complement the histamine deficiency in $H \mathrm{dc}^{-/-}$mice by interkingdom complementation. Our results indicate that histamine-producing $L$. reuteri 6475 protected $H d c^{-1-}$ mice from AOM/DSS-induced inflammationassociated colonic cancer. The bacterial enzyme, HDC, must be present in this microbe to generate histamine as the 
A

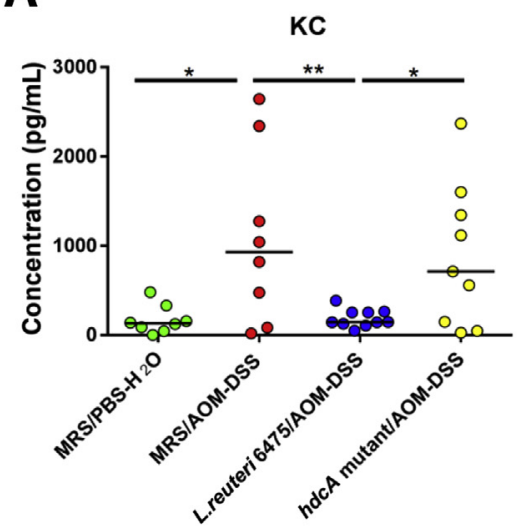

B

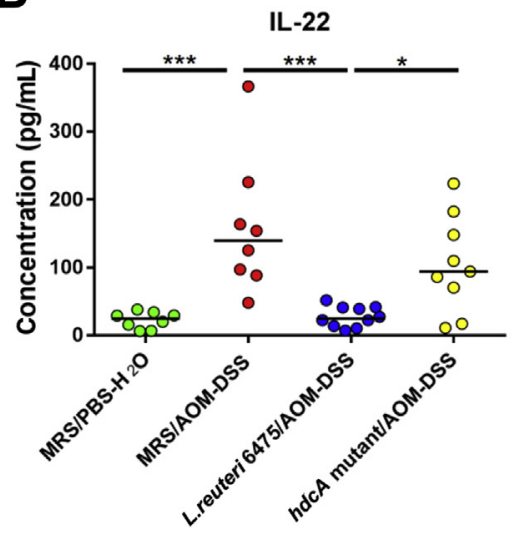

C

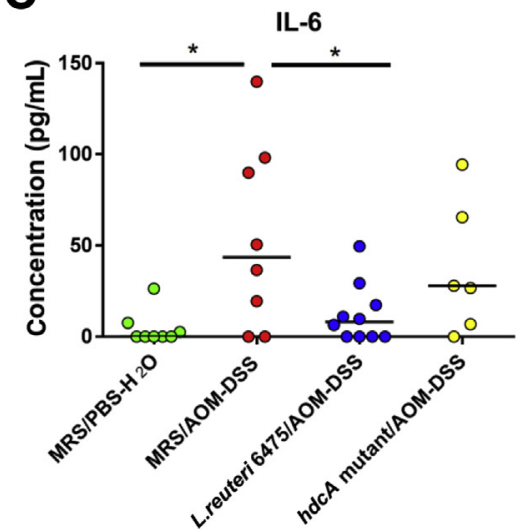

Figure 6 Plasma cytokine concentrations are reduced by histidine decarboxylase (Hdc)A-positive Lactobacillus reuteri. Wild-type L. reuteri 6475 administration significantly decreases the abundances of proinflammatory cytokines keratinocyte chemoattractant (KC) (A), IL-22 (B), and IL-6 (C) in Hdc ${ }^{-1-}$ mouse plasma determined by Luminex assays, whereas the isogenic $L$. reuteri $h d c A$ mutant that lacks the histamine-producing capacity lacks such effects. ${ }^{*} P<0.05$, ${ }^{* *} P<0.01$, and ${ }^{* *} P<0.001$. A0M, azoxymethane; DSS, dextran sulfate sodium; MRS, deMan, Rogosa, Sharpe; PBS, phosphate-buffered saline.

bioactive compound in the intestine, yielding antiinflammatory and antitumorigenic effects (Figure 8).

Histamine receptors on immune cells and the intestinal epithelium are key factors driving the responsiveness of mammalian cells to histamine generated by intestinal microbes. H2R is present on the human intestinal epithelium, ${ }^{32}$ and $\mathrm{H} 2 \mathrm{R}$ has been proposed to play a key role in responses by mammalian cells to histamine generated by luminal gut microbes. ${ }^{33}$ Our prior studies demonstrated that gut microbes such as $L$. reuteri suppressed intestinal inflammation via $\mathrm{H} 2 \mathrm{R} .{ }^{23}$ Gut microbes such as L. reuteri were capable of activating intracellular mammalian protein kinase $\mathrm{A}$ and inhibiting extracellular signal-regulated kinase signaling via histamine receptors. ${ }^{18}$ Past studies documented $\mathrm{H} 2 \mathrm{R}$-mediated signaling via cAMP production and protein kinase $\mathrm{A}$ activation, followed by inhibition of
A

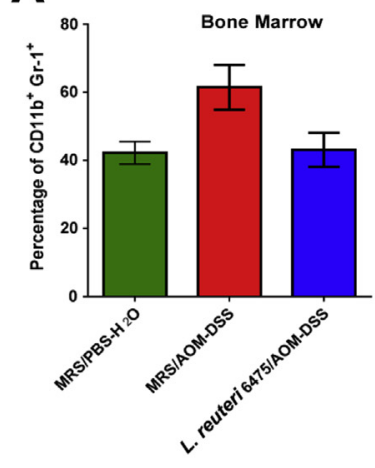

B

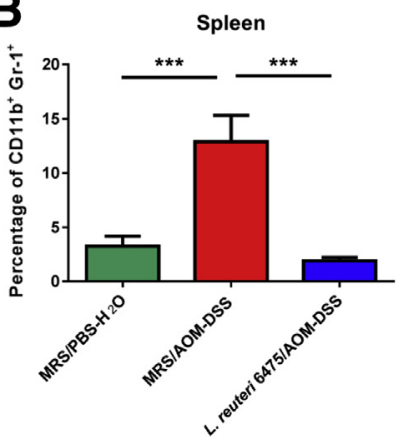

C


Figure 7 Immature myeloid cells (IMCs) in bone marrow and spleen are reduced by Lactobacillus reuteri 6475. A and $\mathbf{B}$ : Percentages of CD11b ${ }^{+} \mathrm{Gr}-1^{+}$IMCs acquired by flow cytometric analysis of the bone marrow (A) and spleen (B) samples of $\mathrm{Hdc}^{-/-}$mice. C: Fluorescence-activated cell sorting analysis shows the

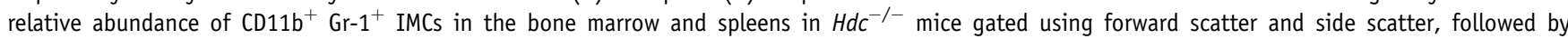
allophycocyanin-cyanine $7\left(\mathrm{Gr}-1^{+}\right)$on $y$ axis and fluorescein isothiocyanate $\left(\mathrm{CD} 11 \mathrm{~b}^{+}\right)$on $x$ axis. $n=3$ to 4 for each group $(\mathbf{A}$ and $\mathbf{B})$. ${ }^{* * * P}<0.001$. A0M, azoxymethane; DSS, dextran sulfate sodium; MRS, deMan, Rogosa, Sharpe; PBS, phosphate-buffered saline. 


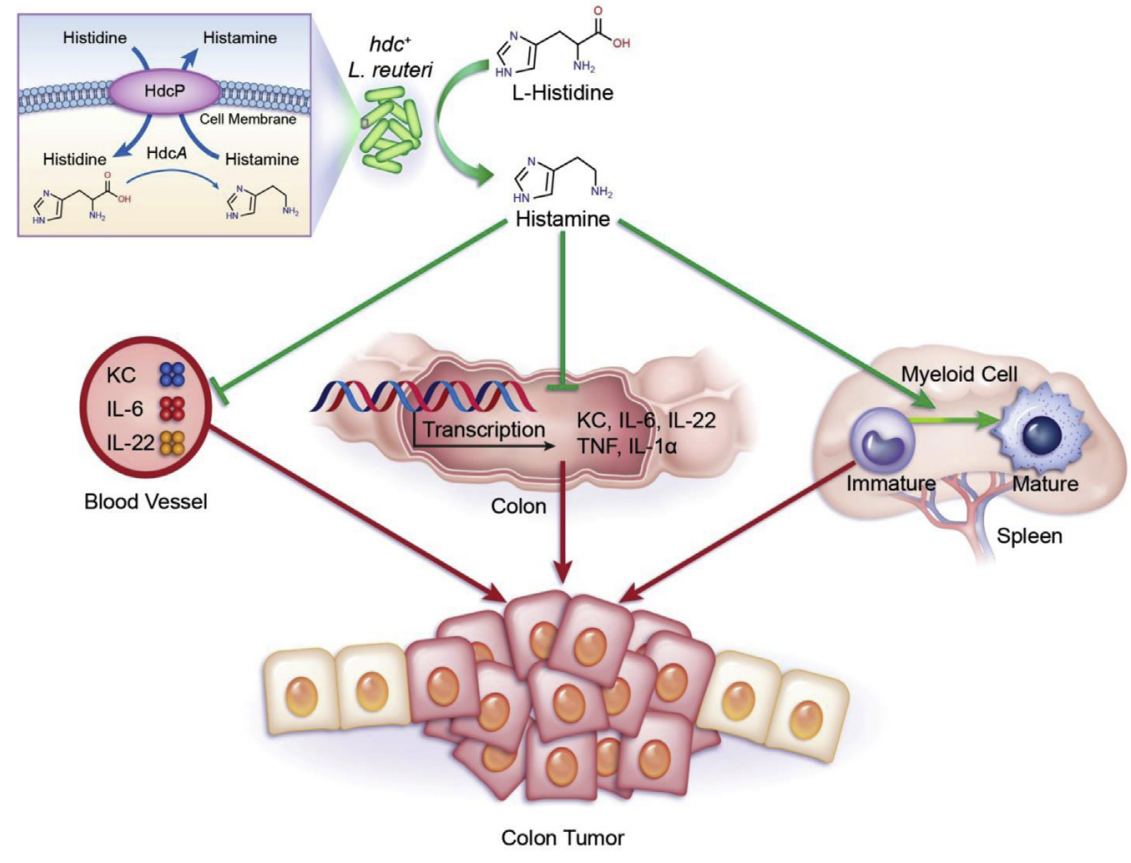

Figure 8 Proposed mechanism describing gut microbe-mediated suppression of inflammationassociated colon carcinogenesis by bacterial histamine production. azoxymethane (AOM)/dextran sulfate sodium (DSS) treatment induces keratinocyte chemoattractant (KC), Il6, Tnf, Il22, and Il1a gene expression in the colon, increases IL-6, IL-22, and KC protein concentrations in mouse plasma, and increases abundance of immature myeloid cells (IMCs) in the spleen. These effects may all contribute to colon carcinogenesis. When $\mathrm{Hdc}^{-1-}$ mice receive $\mathrm{hdc}^{+}$Lactobacillus reuteri, histamine is produced in the intestinal lumen via histidine decarboxylase ( $\mathrm{Hdc}$ ) protein machinery in L. reuteri: L-histidine is converted to histamine by $\mathrm{HdcA}$ and histamine is exported to the gut lumen by histidine-histamine antiporter ( $\mathrm{HdcP}$ ). L. reuteri-derived histamine may activate histamine $\mathrm{H} 2$ receptors (H2Rs) on the intestinal epithelium and trigger anticarcinogenic pathways as indicated by suppression of mammalian cytokine gene expression in the colonic mucosa and reduction of IMCs in the spleen. TNF, tumor necrosis factor.
c-Raf and mitogen-activated protein kinase kinase/ extracellular signal-regulated kinase signaling. ${ }^{18,34-36} \mathrm{Be}-$ sides allergic diseases, other disease phenotypes may be affected by histamine signaling. For example, H2R-mediated signaling may offer protection against nonalcoholic fatty liver disease, ${ }^{37}$ and histamine type 1 receptor-mediated signaling may contribute to irritable bowel syndrome. ${ }^{38}$ The opposing proinflammatory (histamine type 1 receptor) and anti-inflammatory (H2R) effects of histamine receptors may depend on differences in relative tissue distributions of histamine receptors. Histamine generated by microbial or mammalian cells may contribute to tissue homeostasis or pathologic processes based on relative local concentrations of histamine and its receptors. Gut microbes may represent an important source of histamine in mammals with implications for intestinal inflammation and colorectal neoplasia.

Histamine-producing $L$. reuteri suppressed gene expression and production of several cytokines, in contrast to the mutant strain lacking intact bacterial HDC. KC shares many functional properties with IL- $8^{39}$ and has been reported to promote colon cancer growth, progression, and metastasis. ${ }^{40,41} \mathrm{IL}-22$ was also shown to promote gastric cancer cell invasion ${ }^{42,43}$ and colon cancer stemness. ${ }^{44} \mathrm{IL}-6$ has been considered as a key regulator of CRC development, ${ }^{45,46}$ and increased quantities of plasma IL-6 were correlated with a poor prognosis in a variety of cancers, including colon cancer. ${ }^{47}$ Cytokine signaling in CRC provides opportunities for therapeutic intervention, and some clinical trials targeting selected cytokines have been completed or are ongoing. ${ }^{48}$ Our findings on gut microbe-mediated suppression of cancer-associated cytokines may open new avenues for preventive and therapeutic strategies in oncology.
Myeloid cell populations are altered in $H d c^{-1-}$ mice challenged with AOM/DSS. A marked accumulation of CD11 $\mathrm{b}^{+}$ Gr-1 $1^{+}$IMCs in the spleen suggests that myeloid cell maturation programs may be affected by the absence of histamine. $\mathrm{CD} 11 \mathrm{~b}^{+} \mathrm{Gr}-1^{+}$IMC populations have expanded in terms of cell numbers in the spleens of cancer-bearing mice, ${ }^{49}$ with greatly increased IMC populations observed in $\mathrm{Hdc}$-deficient mice. ${ }^{27}$ Our present study shows that oral administration of histamine-producing bacteria reduced the numbers of

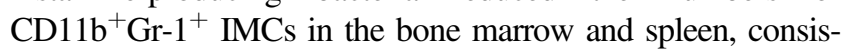
tent with previous studies. ${ }^{27}$ These findings support the notion that exogenous histamine from the gut microbes can stimulate maturation or proliferation of myeloid cells at distant sites.

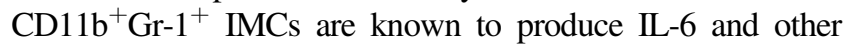
proinflammatory cytokines and may help explain how myeloid cell lineages may contribute to changes in cytokine quantities and inflammation-associated carcinogenesis.

Possible effects of histamine on cancer progression remain controversial. ${ }^{50,51}$ Significantly increased HDC activity was found in tumor specimens in a series of 10 surgical patients with colorectal carcinoma, suggesting possible dysregulation due to genetic abnormalities (epiphenomenon) or a role for HDC enzymatic activity in oncogenesis. ${ }^{52}$ However, a deficiency of endogenous histamine was shown to promote inflammation-associated colonic cancer by promoting the accumulation of $\mathrm{IL}-6$ and $\mathrm{CD} 11 \mathrm{~b}^{+} \mathrm{Gr}-1^{+}$IMCs. $^{27}$ With respect to human cancers, Lactobacillus was shown to be diminished in CRC patients compared with healthy control participants, ${ }^{53,54}$ and some Lactobacillus species have been negatively associated with the risk of colon cancer. ${ }^{55,56}$ Although the correlation between Lactobacillus HDC activity and CRC risk has not been reported, emerging evidence 
indicates that allergy and atopy are inversely associated with glioma development and CRC in patients. ${ }^{57-59}$ Histaminegenerating microbes were recently demonstrated to be increased in the intestines of asthma patients. ${ }^{60}$ These findings suggest that excessive histamine and other mediators in patients with allergic disease may protect individuals from cancer. Our present study showed that patients with elevated patterns of HDC and H2R gene expression demonstrated improved survival rates in human CRC. Future investigations may clarify whether the antitumorigenic effects in the present study by $L$. reuteri are mediated via $\mathrm{H} 2 \mathrm{R}$ and whether differences in $\mathrm{H} 2 \mathrm{R}$ distribution affect cancer phenotypes.

This report highlights the potential importance of luminal conversion of L-histidine to histamine by intestinal microbes as a factor in susceptibility to colitis and colon cancer risk. Histamine represents one of the many microbial metabolites that may have profound consequences for mammalian biology, including but not limited to intestinal immunology and epithelial cell biology. Another important implication is that the mammalian microbiome may modify disease risk by complementing or supplementing deficient functions. Genetic deficiencies in specific mammalian enzymes, as demonstrated by the lack of HDC in this mouse model, may be complemented by supplying missing genes and enzymatic functions via the mammalian gut microbiome. Biogenic amines, such as histamine, may provide microbe-derived signals that augment or alter the functions of immune cells at remote sites, and these findings indicate that microbial metabolites may have an impact on mucosal biology, immune function, and cancer susceptibility. This study summarized findings with a specific microbe (L. reuteri) in the gut, microbial cometabolite (histamine), and the phenotype of inflammation-associated cancer to gain insights into probiotic-mediated modulation of oncogenesis. The importance of an amino acid, L-histidine, as the substrate for luminal conversion suggests a key link between diet and probiotic functions in vivo. Known mammalian drug targets such as histamine receptors may be reconsidered in new disease applications as a result of investigations in mammalian microbiology. These findings may point the way to a deeper understanding of colorectal neoplasia and probiotic-mediated prevention or suppression of epithelialderived cancers.

\section{Acknowledgments}

We thank Eamonn Connolly and Stefan Roos (BioGaia AB, Stockholm) for providing the Lactobacillus reuteri strains and sharing pertinent expertise, and the staff of the Small Animal Imaging facility at Texas Children's Hospital, especially to David A Rendon and M. Waleed Gaber, for positron emission tomography (PET) imaging.

C.G. designed the study, performed experiments, analyzed and interpreted data, and wrote the manuscript; B.P.G. performed flow cytometry and gene expression studies, analyzed data, and wrote the manuscript; Z.S. performed histologic analyses; R.R.S. performed PET imaging analysis; R.F. contributed to cell isolation and flow cytometry; A.M. performed histologic examination and immunohistochemical staining; S.V. performed the Luminex assays for multiplex protein profiling; M.L. helped with mouse sample collections; K.H. and A.H. performed histamine quantification; X.C. and T.C.W. provided the $H d c^{-/}$mice and helpful suggestions for our study and writing of the manuscript; J.V. provided guidance, helped design the experiments, co-wrote the manuscript, and provided funding.

\section{Supplemental Data}

Supplemental material for this article can be found at http://dx.doi.org/10.1016/j.ajpath.2017.06.011.

\section{References}

1. Siegel R, Desantis C, Jemal A: Colorectal cancer statistics, 2014. CA Cancer J Clin 2014, 64:104-117

2. Jess T, Simonsen J, Jorgensen KT, Pedersen BV, Nielsen NM, Frisch M: Decreasing risk of colorectal cancer in patients with inflammatory bowel disease over 30 years. Gastroenterology 2012, 143: 375-381.e1. quiz e13-e14

3. Herrinton LJ, Liu L, Levin TR, Allison JE, Lewis JD, Velayos F: Incidence and mortality of colorectal adenocarcinoma in persons with inflammatory bowel disease from 1998 to 2010. Gastroenterology 2012, 143:382-389

4. Beaugerie L, Svrcek M, Seksik P, Bouvier AM, Simon T, Allez M, Brixi H, Gornet JM, Altwegg R, Beau P, Duclos B, Bourreille A, Faivre J, Peyrin-Biroulet L, Flejou JF, Carrat F; CESAME Study Group: Risk of colorectal high-grade dysplasia and cancer in a prospective observational cohort of patients with inflammatory bowel disease. Gastroenterology 2013, 145:166-175.e8

5. Terzic J, Grivennikov S, Karin E, Karin M: Inflammation and colon cancer. Gastroenterology 2010, 138:2101-2114.e5

6. Louis P, Hold GL, Flint HJ: The gut microbiota, bacterial metabolites and colorectal cancer. Nat Rev Microbiol 2014, 12:661-672

7. Sears CL, Garrett WS: Microbes, microbiota, and colon cancer. Cell Host Microbe 2014, 15:317-328

8. Schwabe RF, Jobin C: The microbiome and cancer. Nat Rev Cancer 2013, 13:800-812

9. Tjalsma H, Boleij A, Marchesi JR, Dutilh BE: A bacterial driverpassenger model for colorectal cancer: beyond the usual suspects. Nat Rev Microbiol 2012, 10:575-582

10. Arthur JC, Perez-Chanona E, Muhlbauer M, Tomkovich S, Uronis JM, Fan TJ, Campbell BJ, Abujamel T, Dogan B, Rogers AB, Rhodes JM, Stintzi A, Simpson KW, Hansen JJ, Keku TO, Fodor AA, Jobin C: Intestinal inflammation targets cancer-inducing activity of the microbiota. Science 2012, 338:120-123

11. Arthur JC, Gharaibeh RZ, Muhlbauer M, Perez-Chanona E, Uronis JM, McCafferty J, Fodor AA, Jobin C: Microbial genomic analysis reveals the essential role of inflammation in bacteria-induced colorectal cancer. Nat Commun 2014, 5:4724

12. Goodwin AC, Destefano Shields CE, Wu S, Huso DL, Wu X, Murray-Stewart TR, Hacker-Prietz A, Rabizadeh S, Woster PM, Sears CL, Casero RA Jr: Polyamine catabolism contributes to enterotoxigenic Bacteroides fragilis-induced colon tumorigenesis. Proc Natl Acad Sci U S A 2011, 108:15354-15359

13. Rowland IR, Rumney CJ, Coutts JT, Lievense LC: Effect of Bifidobacterium longum and inulin on gut bacterial metabolism and carcinogeninduced aberrant crypt foci in rats. Carcinogenesis 1998, 19:281-285

14. Chen CC, Lin WC, Kong MS, Shi HN, Walker WA, Lin CY, Huang CT, Lin YC, Jung SM, Lin TY: Oral inoculation of probiotics 
Lactobacillus acidophilus NCFM suppresses tumour growth both in segmental orthotopic colon cancer and extra-intestinal tissue. Br J Nutr 2012, 107:1623-1634

15. Verma A, Shukla G: Probiotics Lactobacillus rhamnosus GG, Lactobacillus acidophilus suppresses DMH-induced procarcinogenic fecal enzymes and preneoplastic aberrant crypt foci in early colon carcinogenesis in Sprague Dawley rats. Nutr Cancer 2013, 65:84-91

16. Casas IA, Dobrogosz WJ: Validation of the probiotic concept: Lactobacillus reuteri confers broad-spectrum protection against disease in humans and animals. Microb Ecol Health Dis 2000, 12:247-285

17. Liu Y, Fatheree NY, Mangalat N, Rhoads JM: Human-derived probiotic Lactobacillus reuteri strains differentially reduce intestinal inflammation. Am J Physiol Gastrointest Liver Physiol 2010, 299:G1087-G1096

18. Thomas CM, Hong T, van Pijkeren JP, Hemarajata P, Trinh DV, Hu W, Britton RA, Kalkum M, Versalovic J: Histamine derived from probiotic Lactobacillus reuteri suppresses TNF via modulation of PKA and ERK signaling. PLoS One 2012, 7:e31951

19. Madsen KL, Doyle JS, Jewell LD, Tavernini MM, Fedorak RN: Lactobacillus species prevents colitis in interleukin 10 gene-deficient mice. Gastroenterology 1999, 116:1107-1114

20. Pena JA, Li SY, Wilson PH, Thibodeau SA, Szary AJ, Versalovic J: Genotypic and phenotypic studies of murine intestinal lactobacilli: species differences in mice with and without colitis. Appl Environ Microbiol 2004, 70:558-568

21. Schreiber O, Petersson J, Phillipson M, Perry M, Roos S, Holm L: Lactobacillus reuteri prevents colitis by reducing P-selectin-associated leukocyte- and platelet-endothelial cell interactions. Am J Physiol Gastrointest Liver Physiol 2009, 296:G534-G542

22. Preidis GA, Saulnier DM, Blutt SE, Mistretta TA, Riehle KP, Major AM, Venable SF, Barrish JP, Finegold MJ, Petrosino JF, Guerrant RL, Conner ME, Versalovic J: Host response to probiotics determined by nutritional status of rotavirus-infected neonatal mice. J Pediatr Gastroenterol Nutr 2012, 55:299-307

23. Gao C, Major A, Rendon D, Lugo M, Jackson V, Shi Z, Mori-Akiyama Y, Versalovic J: Histamine $\mathrm{H} 2$ receptor-mediated suppression of intestinal inflammation by probiotic Lactobacillus reuteri. MBio 2015, 6:e01358-15

24. Spinler J, Sontakke A, Hollister E, Venable S, Oh LP, Balderas M, Saulnier DMA, Mistretta TA, Devaraj S, Walter J, Versalovic J, Highlander SK: From prediction to function using evolutionary genomics: human-specific ecotypes of Lactobacillus reuteri have diverse probiotic functions. Genome Biol Evol 2014, 6:1772-1789

25. Preidis GA, Versalovic J: Targeting the human microbiome with antibiotics, probiotics, and prebiotics: gastroenterology enters the metagenomics era. Gastroenterology 2009, 136:2015-2031

26. Hemarajata P, Gao C, Pflughoeft KJ, Thomas CM, Saulnier DM, Spinler JK, Versalovic J: Lactobacillus reuteri-specific immunoregulatory gene rsiR modulates histamine production and immunomodulation by Lactobacillus reuteri. J Bacteriol 2013, 195:5567-5576

27. Yang XD, Ai W, Asfaha S, Bhagat G, Friedman RA, Jin G, Park H, Shykind B, Diacovo TG, Falus A, Wang TC: Histamine deficiency promotes inflammation-associated carcinogenesis through reduced myeloid maturation and accumulation of CD11b+Ly6G+ immature myeloid cells. Nat Med 2011, 17:87-95

28. Goswami CP, Nakshatri H: PROGgeneV2: enhancements on the existing database. BMC Cancer 2014, 14:970

29. Preidis GA, Saulnier DM, Blutt SE, Mistretta TA, Riehle KP, Major AM, Venable SF, Finegold MJ, Petrosino JF, Conner ME, Versalovic J: Probiotics stimulate enterocyte migration and microbial diversity in the neonatal mouse intestine. FASEB J 2012, 26:1960-1969

30. Ganesh BP, Richter JF, Blaut M, Loh G: Enterococcus faecium NCIMB 10415 does not protect interleukin-10 knock-out mice from chronic gut inflammation. Benef Microbes 2012, 3:43-50

31. Landskron G, De la Fuente M, Thuwajit P, Thuwajit C, Hermoso MA: Chronic inflammation and cytokines in the tumor microenvironment. J Immunol Res 2014, 2014:149185

32. Sander LE, Lorentz A, Sellge G, Coeffier M, Neipp M, Veres T, Frieling T, Meier PN, Manns MP, Bischoff SC: Selective expression of histamine receptors H1R, H2R, and H4R, but not H3R, in the human intestinal tract. Gut 2006, 55:498-504

33. Ferstl R, Frei R, Schiavi E, Konieczna P, Barcik W, Ziegler M, Lauener RP, Chassard C, Lacroix C, Akdis CA, O'Mahony L: Histamine receptor 2 is a key influence in immune responses to intestinal histaminesecreting microbes. J Allergy Clin Immunol 2014, 134:744-746.e3

34. Funaki C, Hodges RR, Dartt DA: Identification of the Raf-1 signaling pathway used by cAMP to inhibit p42/p44 MAPK in rat lacrimal gland acini: role in potentiation of protein secretion. Invest Ophthalmol Vis Sci 2010, 51:6321-6328

35. Hershenson MB, Chao TS, Abe MK, Gomes I, Kelleher MD, Solway J, Rosner MR: Histamine antagonizes serotonin and growth factor-induced mitogen-activated protein kinase activation in bovine tracheal smooth muscle cells. J Biol Chem 1995, 270:19908-19913

36. Waltereit R, Weller M: Signaling from cAMP/PKA to MAPK and synaptic plasticity. Mol Neurobiol 2003, 27:99-106

37. Yamada S, Guo X, Wang KY, Tanimoto A, Sasaguri Y: Novel function of histamine signaling via histamine receptors in cholesterol and bile acid metabolism: histamine $\mathrm{H} 2$ receptor protects against nonalcoholic fatty liver disease. Pathol Int 2016, 66:376-385

38. Wouters MM, Balemans D, Van Wanrooy S, Dooley J, Cibert-Goton V, Alpizar YA, Valdez-Morales EE, Nasser Y, Van Veldhoven PP, Vanbrabant W, Van der Merwe S, Mols R, Ghesquiere B, Cirillo C, Kortekaas I, Carmeliet P, Peetermans WE, Vermeire S, Rutgeerts P, Augustijns P, Hellings PW, Belmans A, Vanner S, Bulmer DC, Talavera K, Vanden Berghe P, Liston A, Boeckxstaens GE: Histamine receptor H1-mediated sensitization of TRPV1 mediates visceral hypersensitivity and symptoms in patients with irritable Bowel syndrome. Gastroenterology 2016, 150:875-887.e9

39. Oquendo P, Alberta J, Wen DZ, Graycar JL, Derynck R, Stiles CD: The platelet-derived growth factor-inducible $\mathrm{KC}$ gene encodes a secretory protein related to platelet alpha-granule proteins. J Biol Chem 1989, 264:4133-4137

40. Asfaha S, Dubeykovskiy AN, Tomita H, Yang X, Stokes S, Shibata W, Friedman RA, Ariyama H, Dubeykovskaya ZA, Muthupalani S, Ericksen R, Frucht H, Fox JG, Wang TC: Mice that express human interleukin- 8 have increased mobilization of immature myeloid cells, which exacerbates inflammation and accelerates colon carcinogenesis. Gastroenterology 2013, 144:155-166

41. Lee YS, Choi I, Ning Y, Kim NY, Khatchadourian V, Yang D, Chung HK, Choi D, LaBonte MJ, Ladner RD, Nagulapalli Venkata KC, Rosenberg DO, Petasis NA, Lenz HJ, Hong YK: Interleukin-8 and its receptor CXCR2 in the tumour microenvironment promote colon cancer growth, progression and metastasis. Br J Cancer 2012, 106:1833-1841

42. Fukui H, Zhang X, Sun C, Hara K, Kikuchi S, Yamasaki T, Kondo T, Tomita T, Oshima T, Watari J, Imura J, Fujimori T, Sasako M, Miwa H: IL-22 produced by cancer-associated fibroblasts promotes gastric cancer cell invasion via STAT3 and ERK signaling. Br J Cancer 2014, 111:763-771

43. Ji Y, Yang X, Li J, Lu Z, Li X, Yu J, Li N: IL-22 promotes the migration and invasion of gastric cancer cells via IL22R1/AKT/MMP-9 signaling. Int J Clin Exp Pathol 2014, 7: 3694-3703

44. Kryczek I, Lin Y, Nagarsheth N, Peng D, Zhao L, Zhao E, Vatan L, Szeliga W, Dou Y, Owens S, Zgodzinski W, Majewski M, Wallner G, Fang J, Huang E, Zou W: IL-22(+)CD4(+) T cells promote colorectal cancer stemness via STAT3 transcription factor activation and induction of the methyltransferase DOT1L. Immunity 2014, 40:772-784

45. Rokavec M, Oner MG, Li H, Jackstadt R, Jiang L, Lodygin D, Kaller M, Horst D, Ziegler PK, Schwitalla S, Slotta-Huspenina J, Bader FG, Greten FR, Hermeking H: IL-6R/STAT3/miR-34a feedback loop promotes EMT-mediated colorectal cancer invasion and metastasis. J Clin Invest 2014, 124:1853-1867

46. Waldner MJ, Foersch S, Neurath MF: Interleukin-6-a key regulator of colorectal cancer development. Int J Biol Sci 2012, 8:1248-1253 
47. Nagasaki T, Hara M, Nakanishi H, Takahashi H, Sato M Takeyama H: Interleukin-6 released by colon cancer-associated fibroblasts is critical for tumour angiogenesis: anti-interleukin-6 receptor antibody suppressed angiogenesis and inhibited tumour-stroma interaction. Br J Cancer 2014, 110:469-478

48. West NR, McCuaig S, Franchini F, Powrie F: Emerging cytokine networks in colorectal cancer. Nat Rev Immunol 2015, 15:615-629

49. Watanabe S, Deguchi K, Zheng R, Tamai H, Wang LX, Cohen PA, Shu S: Tumor-induced CD11b+Gr-1+ myeloid cells suppress T cell sensitization in tumor-draining lymph nodes. J Immunol 2008, 181:3291-3300

50. Kennedy L, Hodges K, Meng F, Alpini G, Francis H: Histamine and histamine receptor regulation of gastrointestinal cancers. Transl Gastrointest Cancer 2012, 1:215-227

51. Cianchi F, Vinci MC, Masini E: Histamine in cancer: the dual faces of the coin. Cancer Biol Ther 2008, 7:36-37

52. Garcia-Caballero M, Neugebauer E, Campos R, Nunez de Castro I, Vara-Thorbeck C: Increased histidine decarboxylase (HDC) activity in human colorectal cancer: results of a study on ten patients. Agents Actions 1988, 23:357-360

53. Borges-Canha M, Portela-Cidade JP, Dinis-Ribeiro M, LeiteMoreira AF, Pimentel-Nunes P: Role of colonic microbiota in colorectal carcinogenesis: a systematic review. Rev Esp Enferm Dig 2015, 107:659-671

54. Mira-Pascual L, Cabrera-Rubio R, Ocon S, Costales P, Parra A, Suarez A, Moris F, Rodrigo L, Mira A, Collado MC: Microbial mucosal colonic shifts associated with the development of colorectal cancer reveal the presence of different bacterial and archaeal biomarkers. J Gastroenterol 2015, 50:167-179
55. O'Keefe SJ, Chung D, Mahmoud N, Sepulveda AR, Manafe M, Arch J, Adada H, van der Merwe T: Why do African Americans get more colon cancer than Native Africans? J Nutr 2007, 137: $175 S-182 S$

56. Moore WE, Moore LH: Intestinal floras of populations that have a high risk of colon cancer. Appl Environ Microbiol 1995, 61: 3202-3207

57. Amirian ES, Zhou R, Wrensch MR, Olson SH, Scheurer ME, Il'yasova D, Lachance D, Armstrong GN, McCoy LS, Lau CC, Claus EB, Barnholtz-Sloan JS, Schildkraut J, Ali-Osman F, Sadetzki S, Johansen C, Houlston RS, Jenkins RB, Bernstein JL, Merrell RT, Davis FG, Lai R, Shete S, Amos CI, Melin BS, Bondy ML: Approaching a scientific consensus on the association between allergies and glioma risk: a report from the Glioma International Case-Control Study. Cancer Epidemiol Biomarkers Prev 2016, 25:282-290

58. Negri E, Bosetti C, La Vecchia C, Levi F, Tomei F, Franceschi S Allergy and other selected diseases and risk of colorectal cancer. Eur J Cancer 1999, 35:1838-1841

59. Prizment AE, Folsom AR, Cerhan JR, Flood A, Ross JA, Anderson KE: History of allergy and reduced incidence of colorectal cancer, Iowa Women's Health Study. Cancer Epidemiol Biomarkers Prev 2007, 16:2357-2362

60. Barcik W, Pugin B, Westermann P, Perez NR, Ferstl R, Wawrzyniak M, Smolinska S, Jutel M, Hessel EM, Michalovich D, Akdis CA, Frei R, O’Mahony L: Histamine-secreting microbes are increased in the gut of adult asthma patients. J Allergy Clin Immunol 2016, 138:1491-1494.e7 